\section{Immunoreactivity of thymosin beta 4 in human foetal and adult genitourinary tract}

\author{
S. Nemolato, ${ }^{1}$ T. Cabras, ${ }^{2}$ M.U. Fanari, ${ }^{1}$ \\ F. Cau, ${ }^{1}$ D. Fanni, ${ }^{1}$ C. Gerosa, \\ B. Manconi, ${ }^{2}$ I. Messana, ${ }^{2}$ M. Castagnola, ${ }^{3}$ \\ G. Faa'
}

'Dipartimento di Citomorfologia,

Divisione di Anatomia Patologica,

University of Cagliari, Cagliari, Italy;

${ }^{2}$ Dipartimento di Scienze Applicate ai

Biosistemi, Università di Cagliari, Cagliari,

Italy; ${ }^{3}$ sstituto di Biochimica e di

Biochimica Clinica, Università Cattolica

Roma, Italy

\section{Abstract}

Thymosin beta $4\left(\mathrm{~T} \beta_{4}\right)$ is a member of the beta-thymosins family, a family of peptides playing essential roles in many cellular functions. Our recent studies suggested $\mathrm{T} \beta_{4}$ plays a key role in the development of human salivary glands and the gastrointestinal tract. The aim of this study was to analyse the presence of $\mathrm{T} \beta_{4}$ in the human adult and foetal genitourinary tract. Immunolocalization of $\mathrm{T} \beta_{4}$ was studied in autoptic samples of kidney, bladder, uterus, ovary, testicle and prostate obtained from four human foetuses and four adults. Presence of the peptide was observed in cells of different origin: in surface epithelium, in gland epithelial cells and in the interstitial cells. $\mathrm{T} \beta_{4}$ was mainly found in adult and foetal bladder in the transitional epithelial cells; in the adult endometrium, glands and stromal cells were immunoreactive for the peptide; $\mathrm{T} \beta_{4}$ was mainly localized in the glands of foetal prostate while, in the adults a weak $\mathrm{T} \beta_{4}$ reactivity was restricted to the stroma. In adult and foetal kidney, $\mathrm{T} \beta_{4}$ reactivity was restricted to ducts and tubules with completely spared glomeruli; a weak positivity was observed in adult and foetal oocytes; immunoreactivity was mainly localized in the interstitial cells of foetal and adult testis. In this study, we confirm that $\mathrm{T} \beta_{4}$ could play a relevant role during human development, even in the genitourinary tract, and reveal that immunoreactivity for this peptide may change during postnatal and adult life.

\section{Introduction}

Beta-thymosins are N-terminally acetylated peptides of $5 \mathrm{kDa}$ molecular mass, which are composed of 40-44 amino acid residues. ${ }^{1}$
Thymosyn $\beta 4\left(\mathrm{~T} \beta_{4}\right)$ is a 43 -aminoacid peptide, first isolated in human blood platelets; ${ }^{2}$ it is probably an important intracellular modulator of actin polymerization ${ }^{3}$ due to its capacity to interact with monomeric actin. ${ }^{1}$ As an extracellular factor, $\mathrm{T} \beta_{4}$ has been documented to be involved in hormonal activities and in modulating the immune response. ${ }^{1,4}$ It has also been found to have anti-inflammatory efficacy ${ }^{5}$ and to be implicated in cardiac protection, ${ }^{6}$ angiogenesis, ${ }^{7}$ wound healing, ${ }^{8}$ blood coagulation, ${ }^{2}$ hair growth and apoptosis. ${ }^{1,4}$

Recently, a role for $\mathrm{T} \beta_{4}$ has been described in developing foetal salivary glands,${ }^{9}$ in coronary vasculogenesis, ${ }^{10}$ and during the development of different neural cell types in rat brains. ${ }^{11}$ In mouse embryonic kidneys, $\mathrm{T} \beta_{4}$ activity has been shown to increase during development, remaining at high levels during active nephrogenesis. ${ }^{12}$ In rat foetal kidneys, $\mathrm{T} \beta_{4}$ has been identified in differentiating glomeruli, while in adult rats it has been mainly found in collecting ducts. ${ }^{12,13}$ High levels of $\mathrm{T} \beta_{4}$ mRNA were detected in normal human embryonic kidneys and in renal tumors. ${ }^{14}$ Recent studies have also provided new information concerning a role for $\mathrm{T} \beta_{4}$ in human glomerulosclerosis and in kidney fibrosis in adults. ${ }^{15} \mathrm{~T} \beta_{4}$ also plays an important role in the development of the reproductive system. Its secretion has been shown to be modulated by testosterone and gonadotropin in mice and pigs. ${ }^{16-18}$ Increased levels of $\mathrm{T} \beta_{4}$ in the rat ovary have been correlated with the process of luteinization ${ }^{16}$ under the influence of human chorionic gonadotropin, which stimulates $\mathrm{T} \beta_{4}$ gene expression. ${ }^{17}$ The $\mathrm{T} \beta_{4}$ gene is downregulated at transcriptional level by androgen activity in prostate cancer cell culture. ${ }^{19}$ Presence of $\mathrm{T} \beta_{4}$ has been reported during the formation of actin-based pseudopodia in tumoral cells, facilitating cell migration and prostate cancer progression. ${ }^{20}$ Our research has also shown high $\mathrm{T} \beta_{4}$ presence in tumour infiltrating mast cells. ${ }^{21}$ Overall, our research suggests that $\mathrm{T} \beta_{4}$ has an important role in the development of different embryonic and adult organs. Due to controversy in the scientific community regarding the role of $\mathrm{T} \beta_{4}$ in health and disease, this study was aimed at verifying if similarities exist between $\mathrm{T} \beta_{4}$ presence during development and in adult life, and at discussing the putative role played by $\mathrm{T} \beta_{4}$ in both situations. We also found it necessary to better investigate the presence of $\mathrm{T} \beta_{4}$ in the human urinary and reproductive tract of foetuses and adults in order to add new scientific data for a more complete description of the several, and not completely known, functions of this versatile peptide.
Correspondence: Dr. Sonia Nemolato, Dipartimento di Citomorfologia, Divisione di Anatomia Patologica, University of Cagliari, via Ospedale 54, 09124 Cagliari, Italy.

Tel. +39.070 .6092370 - Fax +39.070 .657882 .

E-mail: sonianemolato@libero.it

Key words: thymosin $\beta 4$, genitourinary tract, development.

Contributions: SN conceived and designed the experiments, acquisition of data, performed the experiments, analyzed the data, wrote the manuscript; TC designed the experiments, analyzed the data, wrote the manuscript; MF, FC designed and performed the experiments, contributed reagents/materials/analysis tools; DF, CG conceived and designed the experiments, acquisition of data, performed the experiments, analyzed the data, wrote the manuscript; BM, conceived and designed the experiments, analyzed the data, wrote the manuscript; IM conceived and designed the experiments, performed the experiments, analyzed the data, wrote the manuscript, critical revision of the manuscript and approval of the article; MC, GF conceived, designed and performed the experiments, analyzed the data, wrote the manuscript, critical revision of the manuscript and approval of the article. All authors read and approved the final manuscript.

Acknowledgements: the authors thank Mr. Iganzio Ferru for his secretarial assistance, and Mrs. Sandra Serra and Mrs. Simonetta Paderi for their technical support. They also would like to acknowledge the financial support of the "Fondazione Banco di Sardegna", Cagliari, Sardinia, Italy.

Conflict of interest: the authors report no conflict.

Received for publication: 16 July 2010 .

Accepted for publication: 20 September 2010

This work is licensed under a Creative Commons Attribution 3.0 License (by-nc 3.0).

(C) Copyright S. Nemolato et al., 2010

Licensee PAGEPress, Italy

European Journal of Histochemistry 2010; 54:e43 doi:10.4081/ejh.2010.e43

\section{Materials and Methods}

Four human foetuses, two males and two females, with gestational age ranging from 14 to 27 weeks, and four adults, two males and two females $35,66,68$ and 72 year-old respectively, were selected for this study. In all cases, no pathological changes were evident in the organs examined in this study. We obtained tissue samples at autopsy from each subject including the following segments of the male and female genitourinary tract: kidney, bladder, uterus, ovary, testicle and prostate. Tissue 
samples were fixed in $10 \%$ formalin, routinely processed and paraffin-embedded. Immunohistochemistry was performed on $5 \mu$ m-thick sections, using the labelled streptavidin-biotin complex system (LSAB2, Dako) in a Dako Autostainer (DakoCytomation, Carpintera, CA, USA). Heat-induced antigen retrieval was carried out by steaming unstained sections in Target Retrieval Solution (Dako TRS pH 6.1) for $30 \mathrm{~min}$. Tissue sections were incubated (30 min at room temperature) with the monoclonal anti-thymosin $\beta 4$ antibody (Bachem, Bubendorf, Switzerland). Sections of a reactive human adult lymph node with activated macrophages were used as positive controls. ${ }^{22}$ As a negative control the same procedure was applied omitting the primary antibody.

\section{Ethics statements}

The study protocol and written consent forms were approved by the Ethics Human Studies Committee of University Medical Centre of Cagliari (according to the instructions of the Declaration of Helsinki). Full written consent forms were obtained from the parents of the newborns and all rules were respected. For the specimens from adults, we obtained written consent from their next of kin.

\section{Results}

The immunostaining for $\mathrm{T} \beta_{4}$ appeared homogeneous or granular and was always restricted to the cytoplasm of positive cells. No nuclear reactivity was observed in this study. No significant differences were found in the immunohistochemical pattern for $\mathrm{T} \beta_{4}$ among the four foetuses analyzed, as well as the four adults observed in this study (Table 1). The immunoreactivity for $\mathrm{T} \beta_{4}$ in foetal kidneys paralleled the immunoreactivity in the adult. A weak diffuse cytoplasmic positivity was detected in developmental and mature ducts while the glomeruli were constantly negative (Figure 1a,b). In the bladder, a weak immunoreactivity of the peptide was observed in the immature transitional epithelium, which changed to a coarse granular reactivity in the mature epithelium of the adult bladder (Figure 2a,b). The surrounding stroma showed mild diffuse immunoreactivity of $\mathrm{T} \beta_{4}$ in the foetus and focal in adults (Figure 2b). No immunoreactivity for $\mathrm{T} \beta_{4}$ was observed in foetal endometrial glands. Only scattered stromal cells showed a weak cytoplasmic immunoreactivity (Figure 3a). A mild, granular cytoplasmic immunoreactivity of $\mathrm{T} \beta_{4}$ was present in the endometrial glands of adults, while the absence of any significant immunoreactivity was found in the stroma (Figure $3 \mathrm{~b}$ ). No reactivity for $\mathrm{T} \beta_{4}$ was detected in the foetal or adult prostatic gland epithelium
(Figure 4a,b). We found a diffuse immunoreactivity of $\mathrm{T} \beta_{4}$ in the stroma of adult prostate (Figure $4 \mathrm{~b}$ ), but no reactivity was detected in the foetal prostate stroma (Figure 4a). A fine granular positivity was present in the foetal ovary (Figure 5a), while immunoreactivity of the peptide was homogeneously weak in adult oocytes (Figure 5b). Stroma was negative in

Table 1. Immunoreactivity of T $\beta 4$ in different organs and cells of the human genitourinary tract.

\begin{tabular}{lcc} 
Kidney & Foetus & Aduld \\
Ducts & & \\
Glomeruli & Diffuse & Diffuse \\
Bladder & Negative & Negative \\
Transitional epithelium & Focal & Diffuse \\
Stroma & Negative & Focal \\
\hline Endometrium & & \\
Glands & Negative & Diffuse \\
Stromal cells & Focal & Diffuse \\
Prostate & & \\
Glands & Negative & Focal \\
Stroma & Negative & Diffuse \\
Isolated cells & Focal & Diffuse \\
\hline Ovary & & \\
Oocyte & Focal & Diffuse \\
Testicle & & \\
Spermatic ducts & Negative & Focal \\
Interstitial cells & Focal & Diffuse \\
\hline
\end{tabular}


Figure 1. Kidney. (a) Foetuses: a diffuse cytoplasmic immunoreactivity of $\mathbf{T} \beta_{4}$ is present in developing ducts (arrow). The immature glomuruli are negative (arrowhead). Scale bar: $25 \mu \mathrm{m}$. (b) Adults: primary and secondary ducts show a diffuse cytoplasmic immunoreactivity of $\mathbf{T} \beta_{4}$ (arrow). The glomeruli are negative (arrowhead). Scale bar: $25 \mu \mathrm{m}$.
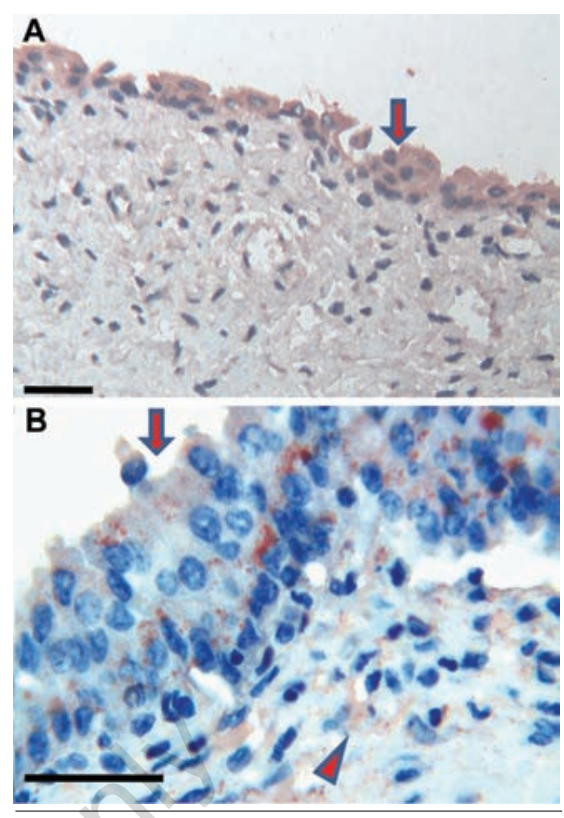

Figure 2. Bladder. (a) Foetuses: the developing transitional epithelium shows a weak and diffuse cytoplasmic immuoreactivity of $T \beta_{4}$ (arrow). The surrounding stroma shows a mild diffuse immunoreactivity of the peptide. Scale bar: $50 \mu \mathrm{m}$. (b) Adults: perinuclear coarse granules, immunoreactive for $\mathrm{T} \beta 4$, are detected in the cytoplasm of transitional epithelium (arrow). The stroma shows a focal positivity of the peptide (arrowhead). Scale bar: $50 \mu \mathrm{m}$.

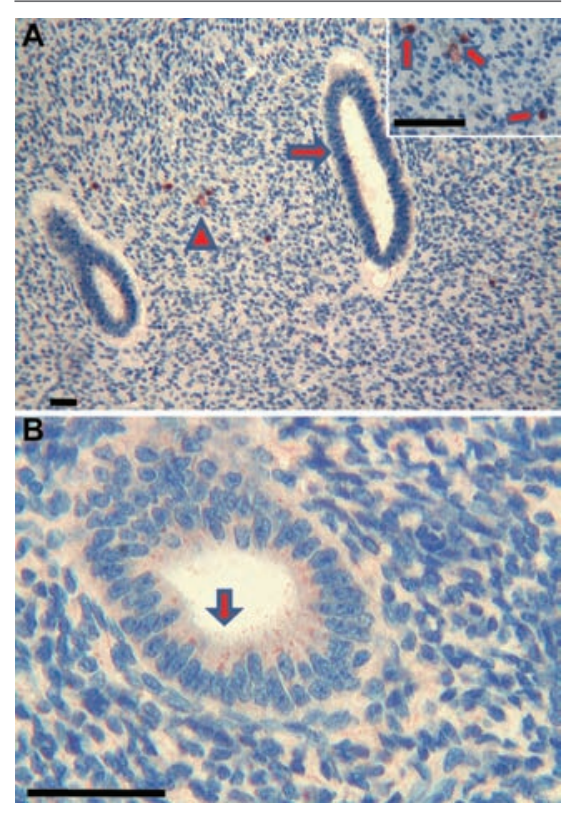

Figure 3. Endometrium. (a) Foetuses: no immunoreactivity of T $\beta 4$ is observed in developing endometrial glands (arrow). Only scattered stromal cells show a weak cytoplasmic immunoreactivity (arrowhead). Scale bar: 100 um. Inset: scattered stromal cells with a cytoplasmic immunoreactivity (arrows). Scale bar: $25 \mu \mathrm{m}$. (b) Adults: a mild granular cytoplasmic immunoreactivity of $T \beta 4$ is observed in the endometrial glands (arrow) while the surrounding stroma has no significant immunoreactivity of the peptide. Scale bar: $25 \mu \mathrm{m}$. 
both adult and in foetal ovaries (Figure 5a,b). The interstitial cells of the adult testicle were strongly positive for $\mathrm{T} \beta_{4}$ while, in the foetus, the same cells showed a mild immunoreactivity for the peptide (Figure 6a,b). Moreover, a mild reactivity of $\mathrm{T} \beta_{4}$ was observed in the spermatic ducts of the adult testicle (Figure 6b).

\section{Discussion}

This is the first comprehensive study that analyzes $\mathrm{T} \beta_{4}$ presence in the human genitourinary tract, and compares the presence of this peptide during development with its reactivity in the adult. We convincingly demonstrate that $\mathrm{T} \beta_{4}$ presence is particular for every organ and, inside each organ, it appears restricted to certain structures or to particular cell types. Many studies in experimental animals and recently in humans suggest that $\mathrm{T} \beta_{4}$ could play a relevant role during development. ${ }^{9,23}$ Our data confirms this hypothesis. In this study, we find that $\mathrm{T} \beta_{4}$ is present during intrauterine life even in the genitourinary tract, and reveal that immunoreactivity for this peptide may change

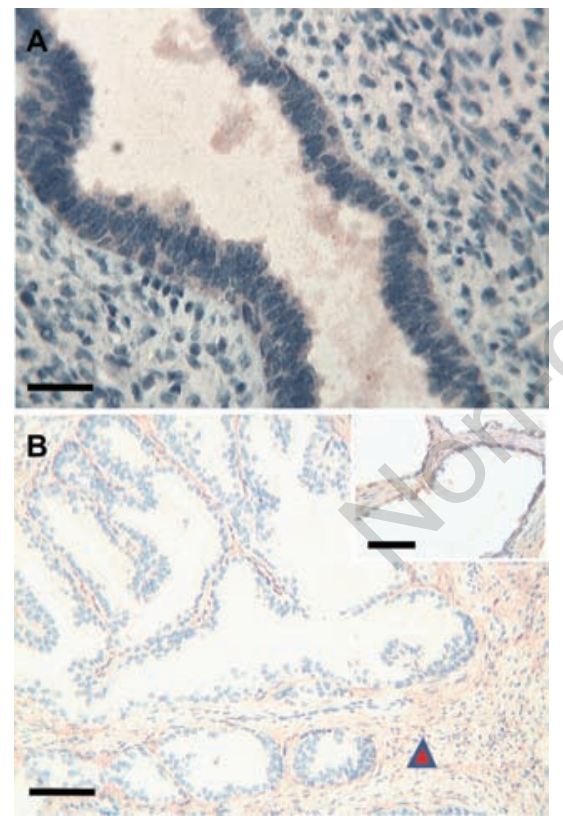

Figure 4. Prostate. (a) Foetuses: no immunoreactivity of $T \beta 4$ is observed in the prostate glands and in the surrounding stroma. Scale bar: $50 \mu \mathrm{m}$. (b) Adults: no significant immuoreactivity of $\mathrm{T} \beta 4$ is detected in the prostate glands. The surrounding stroma shows a diffuse immunoreactivity for the peptide (arrowhead). Scale bar: $50 \mu \mathrm{m}$. Inset: at higher magnification, no significant immunoreactivity for $T \beta 4$ is observed in the prostate gland. Scale bar: $25 \mu \mathrm{m}$. during postnatal life with marked differences between foetal and adult organs. Our previous studies on $\mathrm{T} \beta_{4}$ protein presence in salivary glands ${ }^{9}$ and in the gastrointestinal tract ${ }^{23}$ first disclosed the uneven distribution of the peptide in different organs of the same system and within each organ in the different epithelial and mesenchymal structures and cells. Moreover, in recent years, $\mathrm{T} \beta_{4}$ presence has been reported to increase in different tumors, ${ }^{2426}$ mainly in its infiltrative borders and in their metastastic stage (Nemolato et al, unpublished data). The uneven distribution of $\mathrm{T} \beta_{4}$ among different organs as well as among different cell types within each organ is confirmed by this study also in the genitourinary tract. $\mathrm{T} \beta_{4}$ was clearly present in all organs examined in this study; it was more diffuse in kidney, adult bladder and in interstitial cells of the testis.

Interestingly, we found differences in this study between foetal and mature organs. In general, we found direct associations between presence of $\mathrm{T} \beta_{4}$ and the degree of development in all the organs tested. The presence of a relationship between $\mathrm{T} \beta_{4}$ presence and the developmental status does not coincide with our previous data regarding the gastrointestinal tract. ${ }^{23}$ In previous studies, $\mathrm{T} \beta_{4}$ presence patterns were characterized by a higher presence in the foetus and by a marked decrease in the adult suggesting a major role of $\mathrm{T} \beta_{4}$ during embryogenesis. This hypothesis was confirmed by our studies of $\mathrm{T} \beta_{4}$ content in human saliva, ${ }^{9}$ which clearly showed high $\mathrm{T} \beta_{4}$ levels during gestation followed by the disappearance of the peptide in the adult saliva. Our study reinforces our hypothesis that $\mathrm{T} \beta_{4}$ functions are not totally known and stresses the different function this peptide could play in different human organs, not only during development, but also even during adult life. Some peculiar features related to the patchy $\mathrm{T} \beta_{4}$ distribution in different organs deserve to be noted in: i) kidney restriction of $\mathrm{T} \beta_{4}$ reactivity to ducts and tubules with completely spared glomeruli (Figure 1a,b); ii) a positivity in the oocytes of the ovary (Figure 5a,b); iii) immunoreactivity restricted to interstitial cells in the testis (Figure 6a,b). What is the relationship between these very different types of cells? For the time being, we have no clear answer. The immunoreactivity of oocytes of $\mathrm{T} \beta_{4}$ in the foetal ovary and its increase in the

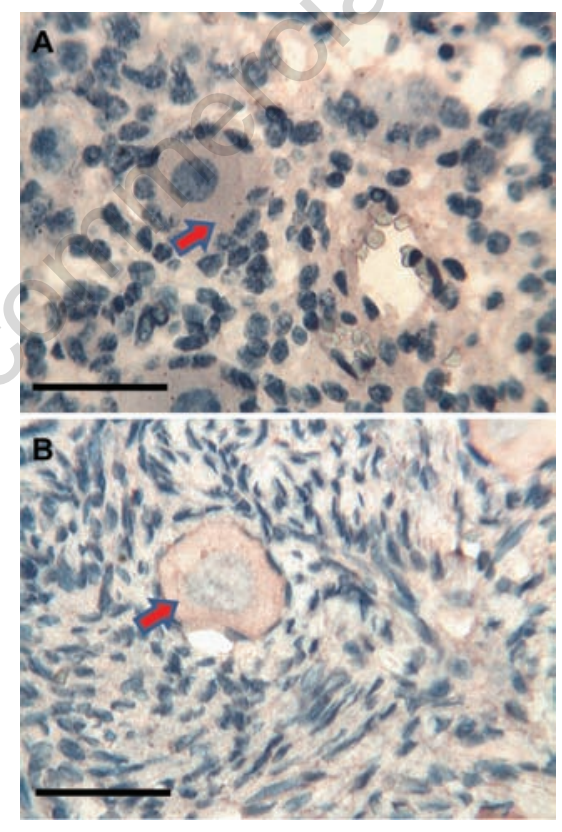

Figure 5. Ovary. (a) Foetuses: scattered $T \beta 4$ reactive fine granules are present in the cytoplasm of the oocyte (arrow). A weak diffuse immunoreactivity of the surrounding stroma is detected. Scale bar: 25 $\mu \mathrm{m}$. (b) Adults: a weak and homogeneous cytoplasmic immunoreactivity for $\mathrm{T} \beta 4$ is detected in the oocyte of the primary follicle (arrow). A weak diffuse immunopositivity in the surrounding stroma is observed. Scale bar: $25 \mu \mathrm{m}$.

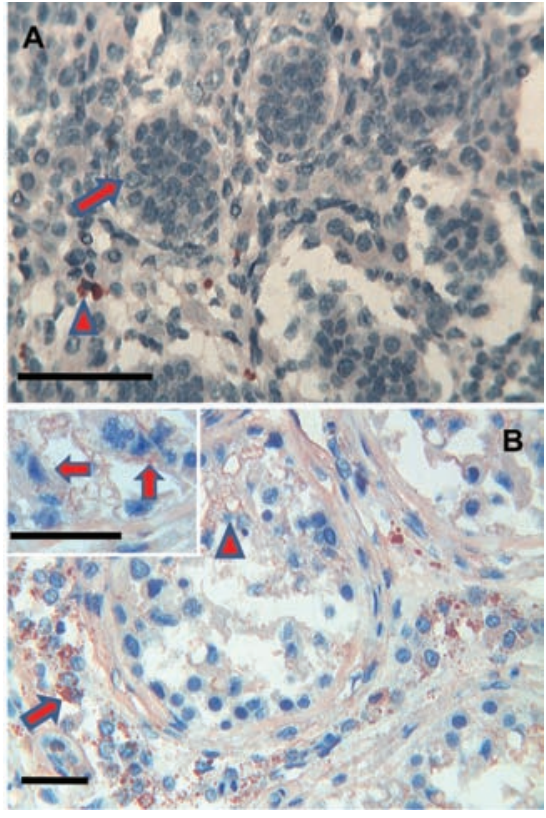

Figure 6. Testicle. (a) Foetuses: no immunoreactivity for $\mathrm{T} \beta 4$ is observed in the immature spermatic ducts (arrow). A mild cytoplasmic immunoreactivity of the peptide is observed in isolated interstitial cells (arrowhead). Scale bar: $25 \mu \mathrm{m}$. (b) Adults: a granular cytoplasmic immunoreactivity of $\mathrm{T} \beta 4$ is detected in the interstitial cells of the testicle (arrow). A weak immunoreactivity is observed in the cells of the spermatic ducts (arrowhead). Scale bar: $50 \mu \mathrm{m}$ Inset: cells of the spermatic ducts with a weak immunoreactivity (arrows). Scale bar: $25 \mu \mathrm{m}$. 
adult oocytes indicates a role of the peptide not only in germ cell development but also in its maintenance during adult life.

In this study, $\mathrm{T} \beta_{4}$ was frequently detected not only inside of cells but also in the stroma surrounding gland structures both in foetuses and in adults. Considering the fact that the extracellular forms of beta-thymosins have been shown to selectively prevent neuronal cell death, ${ }^{27}$ we can speculate that the same role could be played by $\mathrm{T} \beta_{4}$ in the genitourinary tract during development. This role should be elucidated in further studies. Finally, our study clearly shows that further work is required to better understand the presence of $\mathrm{T} \beta_{4}$ and its impacts on development and on biological behaviour of adult cells in different human organs, which confirms $\mathrm{T} \beta_{4}$ as a versatile peptide with several, mostly unknown important functions in human health and disease.

\section{References}

1. Mannherz HG, Hannappel E. The beta-thymosins: intracellular and extracellular activities of a versatile actin binding protein family. Cell Motil Cytoskeleton 2009; 66:839-51.

2. Safer D, Golla R, Nachmias VT. Isolation of a 5-kilodalton actin-sequestering peptide from human blood platelets. PNAS USA 1990;87:2536-40.

3. Dominguez R. The $\beta$-Thymosin/WH2 fold. Multifunctionality and structure. Ann N Y Acad Sci 2007;1112:86-94.

4. Paulussen M, Landuyt B, Schoofs L, Luyten W, Arckens L. Thymosin beta 4 mRNA and peptide expression in phagocytic cells of different mouse tissues. Peptides 2009; 30:1822-32.

5. Young JD, Lawrence AJ, MacLean AG, Leung BP, McInnes IB, Canas B et al. Thymosin beta- 4 sulfoxide is an antiinflammatory agent generated by monocytes in the presence of glucocorticoids. Nat Med 1999;5:1424-7.

6. Wessels A, Perez-Pomares JM. The epicardium and epicardially derived cells (EPDCs) as cardiac stem cells. Anat Rec A Discov Mol Cell Evol Biol 2004;276:43-57.

7. Smart N, Rossdeutsch A, Riley PR.
Thymosin $\beta 4$ and angiogenesis: modes of action and therapeutic potential. Angiogenesis 2007;10:229-41.

8. Sosne G, Szliter EA, Barrett R, Kernacki KA, Kleinman H, Hazlett LD. Thymosin beta-4 promotes corneal wound healing and decreases inflammation in vivo following alkali injury. Exp Eye Res 2002;74:2939 .

9. Nemolato S, Messana I, Cabras T, Manconi B, Inzitari R, Fanali C et al. Thymosin beta (4) and beta (10) levels in preterm newborn oral cavity and foetal salivary glands evidence a switch of secretion during foetal development. PLoS One 2009; 4:e5109.

10. von Kodolitsch Y, Ito WD, Franzen 0, Lund GK, Koschyk DH, Meinertz T. Coronary artery anomalies Part I: recent insights from molecular embryology. Z Kardiol 2004;93:929-37.

11. Lin SC, Morrison-Bogorad M. Developmental expression of mRNAs encoding thymosins beta- 4 and beta 10 in rat brain and other tissues. $\mathrm{J}$ Mol Neurosci 1990;2:35-44.

12. Guinobert I, Viltard M, Piquemal D, Elalouf JM, Marti J, Lelièvre-Pégorier M. Identification of differentially expressed genes between fetal and adult mouse kidney:candidate gene in kidney development. Nephron Physiol 2006;102:81-91.

13. Mora CA, Baumann CA, Paino JE, Goldstein AL, Badamchian M. Biodi stribution of synthetic thymosin beta 4 in the serum, urine, and major organs of mice. Int J Immunopharmacol 1997;19:1-8.

14. Hall AK. Differential expression of thymosin genes in human tumors and in developing human kidney. Int $\mathrm{J}$ Cancer 1991;48:672-7.

15. Ma LJ, Fogo AB. PAI-1 and kidney fibrosis. Front Biosci 2009;14: 2028-41.

16. Hall AK, Aten R, Behrman HR. Thymosin gene expression is modulated by pregnant mare's serum gonadotropin, human chorionic gonadotropin, and prostaglandin F2 alpha in the immature rat ovary. Endocrinology 1991;128:951-7.

17. Hall AK, Aten R, Behrman HR. Differential modulation of thymosin genes in the immature rat ovary by gonadotropins. Mol Cell Endocrinol 1991;79:37-43.
18. Wise TH. Developmental changes of thymosin alpha 1 and beta 4 in male and male castrated pigs: modulation by testosterone and human chorionic gonadoropin. Biol Reprod 1992;46:892-7.

19. Iguchi K, Ito M, Usui S, Mizokami A, Namiki M, Hirano K. Downregolation of thymosin beta 4 expression by androgen in prostate cancer LNCaP cells. J Androl 2008; 29:207-12.

20. Ito $\mathrm{M}$, Iguchi $\mathrm{K}$, Usui $\mathrm{S}$, Hirano $\mathrm{K}$. Overexpression of thymosin beta 4 increases pseudopodia formation in LNCaP prostate cancer cells. Biol Pharm Bull 2009;32:1101-4.

21. Nemolato S, Cabras T, Fanari MU, Cau F, Fraschini M, Manconi B, et al. Thymosin beta 4 expression in normal skin, colon mucosa and in tumor infiltrating mast cells. Eur J Histochem 2010;54:e3.

22. Kannan L, Rath NC, Liyanage R, Lay JO. Identification and characterization of thymosin $\beta-4$ in chicken macrophages using whole cell MALDI-TOF. Ann N Y Acad Sci 2007;1112:425-34.

23. Nemolato S, Cabras T, Cau F, Fanari MU, Fanni D, Manconi B, et al. Different Thymosin Beta 4 Immunoreactivity in Foetal and Adult Gastrointestinal Tract. PLoS One 2010;5: e9111.

24. Wang WS, Chen PM, Su Y. Colorectal carcinoma: from tumorigenesis to treatment. Cell Mol Life Sci 2006;63:663-71.

25. Otto AM, Muller CSG, Huff T, Hannappel E. Chemotherapeutic drugs change actin skeleton organization and the expression of beta thymosins in human breast cancer cells. J Cancer Res Clin Oncol 2002;128: 247-56.

26. Ji P, Diederichs S, Wang W, Boing S, Metzger R, Schneider PM, et al. MALAT-1, a novel noncoding RNA, and thymosin beta 4 predict metastasis and survival in early-stage non-small cell lung cancer. Oncogene 2003;22:8031-41.

27. Choi SY, Kim DK, Eun B, Kim K, Sun W, Kim H. Anti-apoptotic function of thymosin beta in developing chick spinal motoneurons. Biochim Biophys Res Commun 2006;346:872-8. 